\title{
FUNCTIONALLY GRADED ADDITIVE MANUFACTURING: A TEACHING CASE STUDY OF INEX-ADAM
}

\author{
I. R. Kabir $\bowtie$, G. H. Loh and E. Pei \\ Brunel University London, United Kingdom \\ $\triangle$ israt.kabir@brunel.ac.uk
}

\begin{abstract}
The multidisciplinary nature and lack of comprehensive 'materials-product-manufacturing' knowledge of Functionally Graded Additive Manufacturing (FGAM) require training to support the future Additive Manufacturing experts. INEX-ADAM, an EU funded project is building a transnational platform to promote FGAM. Brunel University London conducted two-day workshop on FGAM at the University of Zagreb in Croatia with academics and industry professionals. The workshop will strengthen the research capabilities to harness the potential of the FGAM and mitigate the constraints to industrial applications.
\end{abstract}

Keywords: additive manufacturing, functional modelling, design guidelines, design methodology, design education

\section{Introduction}

Functionally Graded Additive Manufacturing (FGAM) is an emerging technology that offers a huge potential for novel industrial applications. However, the lack of comprehensive knowledge constrains its progress and promotion (Loh et al., 2018). Design for FGAM requires a multidisciplinary understanding on the functionality of the component, selection of material, identify the AM technologies to build the components, defining and describing the material distribution, gradient dimension and so on (Pei and Loh, 2019). Therefore, the INEX-ADAM platform enables a collaborative approach to create and transfer the knowledge for this promising technology.

INEX-ADAM, Increasing Excellence in Advanced Additive Manufacturing, is an EU-funded project under the Horizon 2020 scheme. The project is coordinated by the University of Zagreb (UNIZAG) and supported by the Brunel University London (UBRUN), Lunds Tekniska Högskola (LTH), Montanuniversität Leoben (MUL) and the Technology Institute on Metal-Processing, Wood, Furniture, Packaging and Related Industries (AIDIMME). The principle goal of INEX-ADAM is to widen the participation for collaborative research among the consortium partners and support UNIZAG with technical assistance and knowledge in the field of AM. The project consists of five Work packages (WP). UBRUN is leading WP-2 for synergy strengthening and conducting the data mapping research. The WP-2 outcome will enable a long-term view of synergy strengthening for cooperation in the field of advanced AM. From the mapping study, after measuring the level of knowledge, resources and expertise of each project partner, a high-level plan for knowledge transfer was set out within a predefined framework. A curriculum for training and workshops was proposed by each supporting partner to conduct an education programme for the next work package (Pei and Kabir, 2019). 
The FGAM workshop is a part of that education programme led by UBRUN to support UNIZAG with knowledge and applications of FGAM. UBRUN is an established institution a wide range of engagement with education, research and industry projects related to AM. The Department of Design of UBRUN is directly involved in the INEX-ADAM project. FGAM is one the key AM expertise of the department including AM Standards, Innovation Process and Management and Sustainable Business Models for Manufacturing (Pei and Kabir, 2019a). Worldwide initiatives were already taken on AM education to develop a standard knowledge transfer framework (Simpson et al., 2017). However, specific courses or trainings on FGAM are yet not developed. Therefore, utilising the INEX-ADAM platform a workshop-based teaching case study on FGAM was conducted by UBRUN for the first time to realise the need and gaps in development and transmission of knowledge to the associated stakeholders (academics, researchers, industries and policy makers).

Therefore, as a part of the education programme, UBRUN conducted a one-day workshop on FGAM at UNIZAG in Croatia. The workshop provided a comprehensive view of FGAM in theory and practice of design, manufacturing and applications to a small group of academics and researchers of UNIZAG. This paper presents the teaching and assessment methods, structure, brief description of the teaching contents and the evaluation process of the learning outcomes from the workshop; which ultimately enabled the partner organisations to enhance the FGAM research capacity and increase the knowledge of FGAM to support emerging medical, automotive and tooling industries.

\section{FGAM workshop}

UBRUN conducted a one-day workshop in Functionally Graded Materials (FGM) in AM. The training aimed to help learners develop an understanding of the concept and process chain of FGAM. It helped them to recognise the benefit and challenges in the applications and design of FGAM parts. The set learning objectives (LO) for the workshop are as follows:

- Demonstrate the principle, function and classification of FGAM

- Apply the knowledge in design engineering parts for FGAM

- Utilise the processing technologies of FGAM in research and practical cases

\subsection{Teaching methods}

The workshop on FGAM was a content-based teaching on concept, challenges and applications of FGAM and standard design guidelines for FGAM. The workshop-based teaching method was chosen for a small group of learners, enhancing staff development of UNIZAG and support them in learning and teaching on FGAM. The workshop-based teaching model is commonly practiced in education of experimental sciences including engineering, mathematics, product design, writing, and visual arts (Fry et al., 2009). Many UK and international Higher Education Institutions (HEI) run 2-hour or 4-hour workshops for their staff development programme (Learning and Teaching Hub @Bath, 2020). The Department of Design of UBRUN, expert HEI in industrial product design and innovation, conducts many workshops for idea generation and knowledge transfer activities (Brunel University London, 2020). The workshop not only serves as a delivery method but also as an assessment tool. It creates an interactive environment which provides opportunities of the formative assessment in measuring learners' background knowledge and finding gaps and needs in skills and education. This formative assessment helps further develop the teaching curricula to reinforce or extend learning process (NFER, n.d.).

Moreover, the workshop-based teaching is useful to teach a small group of adult academic and researchers possessing highly learning and teaching abilities. Techniques such as seminar, workshop, symposium, group discussions, etc. can enable adults to learn effectively (Palis and Quiros, 2014). Employing such strategies including case studies and role playing are found to be most useful in this setting (Culatta, 2020).

Therefore, the FGAM workshop was delivered using mixed teaching and assessment tools including content-focused lecture, group discussion and learner's activities. The participants informed the knowledge on design, manufacturing and applications of FGAM through the lectures. The group discussions were embedded in the lectures to make the course more inclusive and measure their background knowledge. Learners' participation in an activity called FGAM project of literature search, idea generation and 
communications with peers created an experiential and active learning environment which motivated the learners. This provided an opportunity of summative assessment to evaluate the LO through a group flipchart presentation at the end of this activity. Finally, the triangulation method was carried out to validate the assessment of LO by an online survey requesting participants' feedback.

\subsection{The structure of teaching/training}

Table 1 shows the teaching plan for the one-day workshop. The workshop started at 9:30 am in the morning and ran until 16:45 pm. First one hour of the lecture was intensely content focused with a few discussions. In the morning time, learners' minds are energetic and capable of absorbing information fast. The lecture started with the introduction and conception of FGAM followed by design, modelling and manufacturing technologies for FGAM. After the lunch break, the workshop conducted a projectbased activity to make learners more inclusive with the contents based on an active learning approach. It also helped assess their perceived knowledge from the lectures. The contents of the lecture and activities are described briefly in the following sub-sections.

Table 1. FGAM workshop plan

\begin{tabular}{|c|c|c|}
\hline Time & Topics & Materials \& Activities \\
\hline $09.30-10.30$ & $\begin{array}{l}\text { Lecture and Discussion } \\
\text { Introduction to Additive Manufacturing (AM) } \\
\text { The concept of Functionally Graded Additive Manufacturing } \\
\text { (FGAM) } \\
\text { The advances of FGAM } \\
\text { The design, modelling and manufacturing methodologies of } \\
\text { FGAM } \\
\text { AM technologies for FGAM }\end{array}$ & $\begin{array}{l}1 \text { lecture note (PowerPoint } \\
\text { file), Post-it notes and pens }\end{array}$ \\
\hline $10.30-10.45$ & Break & \\
\hline $10.45-12.00$ & $\begin{array}{l}\text { Lecture } \\
\text { AM technologies for FGAM (Cont.) }\end{array}$ & $\begin{array}{l}1 \text { lecture note (PowerPoint } \\
\text { file) }\end{array}$ \\
\hline $12.00-13.00$ & Lunch Break & \\
\hline $13.00-14.30$ & $\begin{array}{l}\text { Lecture } \\
\text { Types of FGMs applications using Additive Manufacturing } \\
\text { Activity (60 minutes) } \\
\text { Understanding the FGAM process chain and applications }\end{array}$ & $\begin{array}{l}1 \text { lecture note (PowerPoint } \\
\text { file), Post-it notes and pens }\end{array}$ \\
\hline $14: 30-14: 45$ & Break & \\
\hline $14: 45-16: 45$ & $\begin{array}{l}\text { Lecture } \\
\text { Summary of the lectures } \\
\text { Activity (Cont. } 90 \text { minutes) } \\
\text { Presentation on the Understanding the FGAM process chain } \\
\text { and applications }\end{array}$ & $\begin{array}{l}1 \text { lecture note (PowerPoint } \\
\text { file), Post-it notes and pens }\end{array}$ \\
\hline
\end{tabular}

\subsubsection{Introduction and conception of FGAM}

FGAM is a layer-by-layer fabrication process that involves gradationally varying the material organisation within a component to achieve an intended function (Loh et al., 2018). Figure 1 presents the differences between conventional multi-material AM and FGAM. A schematic presentation shows the sharp interface in multi-material composite structure and a smooth transition of gradient zones in FGAM. At this point, the trainer called on a group discussion on the difference between conventional $\mathrm{AM}$ and FGAM, to measure learners' perception of the advanced FGAM technology. The group discussion activity was described in the following sub-section (see, section 2.3) of this paper. 


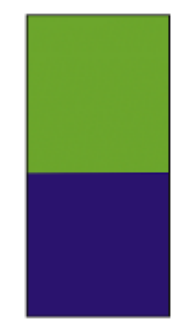

(a) Sharp interface

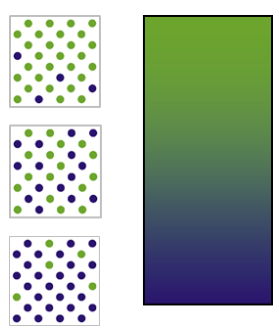

(b) Smooth transition in gradient zones

Figure 1. Difference in transition zones between (a) Conventional multi-material AM and (b) FGAM (Loh et al., 2018)

\subsubsection{Design, modelling and manufacturing technologies of FGAM}

The design for FGAM integrates material composition and distribution including the geometry of the part which called performance modelling. 3D modelling for FGAM uses voxels to define the characteristics of a 3D part of the geometry. The voxel is a three-dimensional cube or a 3D pixel. It captures the information about the object's volume rather than just its surface, enabling continuous modification of material's composition throughout the fabrication process. This method of designing FGAM is called voxel modelling. Some potentially suitable CAD file formats to produce FGAM parts are AMF (Additive Manufacturing Format), FAV (Fabricatable Voxel) and 3MF (3D Manufacturing Format), in which FAV follows voxel-based approach (Loh et al., 2018). The trainer presented a video tutorial of FGAM modelling using VoxCAD open-source voxel modelling software (Hiller, 2011) to inform about the cutting-edge modelling techniques. This voxel-based approach enabled to produce more efficiently engineered structures with customizable site-specific properties tailored at small sections that would be impossible using traditional production methods. Here, the benefits of FGAM were discussed from the learners' perspective through a group discussion activity presented later in section 2.3.

The overall process chain in the design and manufacturing FGAM part is divided into several steps presented in Figure 2. The design phase is a critical and crucial step to ensure manufacturing accuracy and quality of the component.

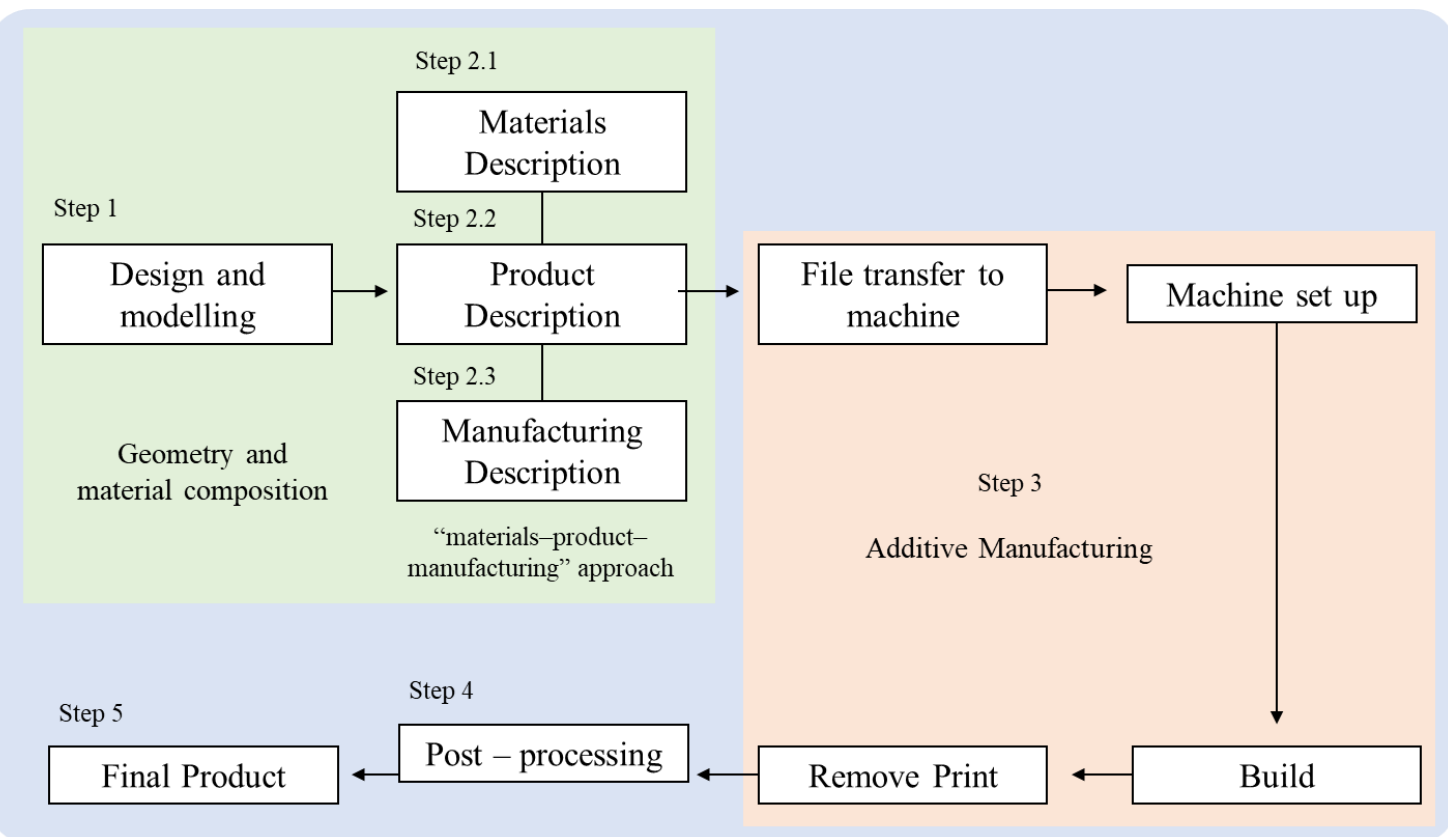

Figure 2. The FGAM process flow from design to manufacturing (Loh et al., 2018)

The FGAM manufacturing techniques were discussed elaborately supported by existing literature and applications. The knowledge about manufacturing technologies for FGAM is crucial as it helps 
learners understand the process mechanisms and qualify the techniques based on applications and design of the parts. Six types of AM technologies are used to manufacture FGAM parts (Pei and Loh, 2019). They are Material Extrusion (ME), Vat Photopolymerisation or Stereolithography (SLA), Powder Bed Fusion (PBF), Material Jetting (MJ) and Sheet Lamination (SL).

\subsubsection{Novel FGAM applications}

FGAM technologies have huge potential for several existing and novel applications. Table 2 presents a list of major fields of FGAM applications including aerospace, automobiles, biomedical and structural industries.

Table 2. The engineering applications of FGAM parts (Loh et al., 2018)

\begin{tabular}{|l|l|}
\hline \multicolumn{1}{|c|}{ Applications } & \multicolumn{1}{c|}{ FGAM parts } \\
\hline Aerospace & $\begin{array}{l}\text { Rocket engines component, heat exchange panels, reflectors, solar panels, camera } \\
\text { housing, turbine wheels, turbine blade, nose caps. }\end{array}$ \\
\hline Automotive & $\begin{array}{l}\text { Engine cylinder liners, leaf springs, spark plugs, the drive shafts, the flywheels, } \\
\text { car body parts, window glass and racing car brakes. }\end{array}$ \\
\hline Biomedical & Implants, Skeletal replacement implants. \\
\hline Defence & Bullet-proof vests, sword, armour plates. \\
\hline Energy & $\begin{array}{l}\text { The inner wall of nuclear reactor, solar cells, tubes and pressure vessels, piezo- } \\
\text { electric ultrasonic transducer, turbine blade coatings. }\end{array}$ \\
\hline Others & Cutting tool and die, razor blades \\
\hline
\end{tabular}

\subsection{List of activities}

\subsubsection{Panel discussions}

To make this content-focused workshop interactive and encourage active learning, the trainer included some discussion activities during the lectures. On a given time, the participants were asked to jot down their opinions on post-it notes either individually or in a group. The instructor collected all their comments and placed them on the board followed by a panel discussion. Figure 3(a) and 3(b) captured learners' perceptions on the difference between multi-material AM and FGAM along with the benefits of FGAM. This activity helped to measure the existing knowledge of the participants and help the educator understand the need for information respective to that setting. Another discussion was also run to identify the current technological limitations and challenges to enable the production of FGAM parts in Croatia. Here, the participants formed a group and expressed their understanding based on the provided hand-outs and use of internet resources on possible strategies and recommendations required to overcome those barriers. Figure 3(c) presents learners' understanding of limitations and their solutions in three categories of FGAM process chain including 1) design and modelling, 2) CAD tools and workflow and 3) AM technologies, build parameters.

\subsubsection{FGAM project ( 90 mins)}

At the end of the workshop, a short project-based activity was carried out enabling the participants to gain a good understanding of the FGAM process chain from design to manufacture and discover potential areas for application. During the activity proposal in the first 40 minutes, the learners were asked to work in pair to select a potential application of FGAM using the existing literature and case studies available online. They were asked to identify the key features of the geometry, type of FGAM composition and the materials used for the product followed by suggesting a possible AM processing method and process chain to fabricate the component. The project outcome was a two-page flip chart describing the concept of potential application with the AM processing methods and building strategies. In the next 90 minutes session, the participants presented their findings as activity deliverable. Figure 4 shows the flip-chart presentations for three groups showing both existing and novel applications of FGAM in sports, defence and automotive fields along with their proposed design and processing workflows. 


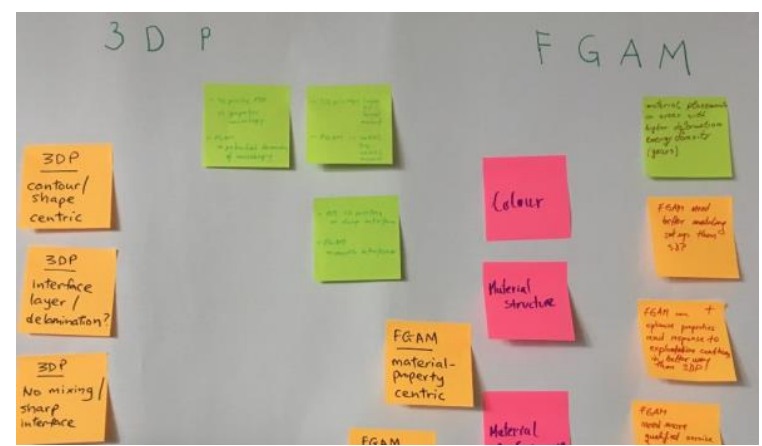

(a)

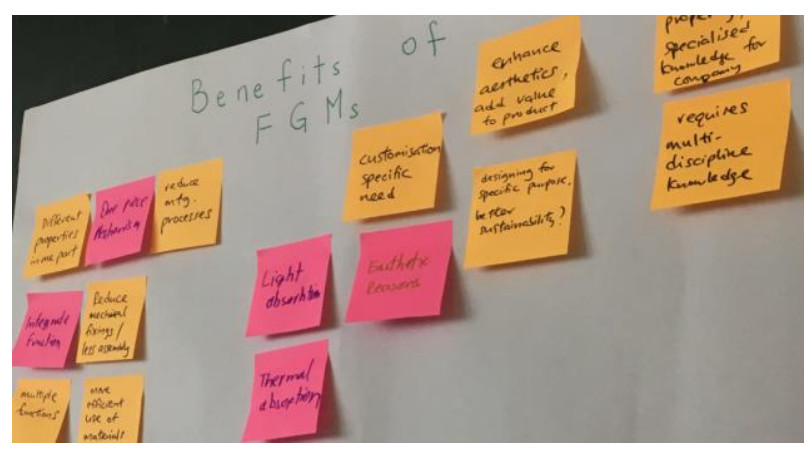

(b)

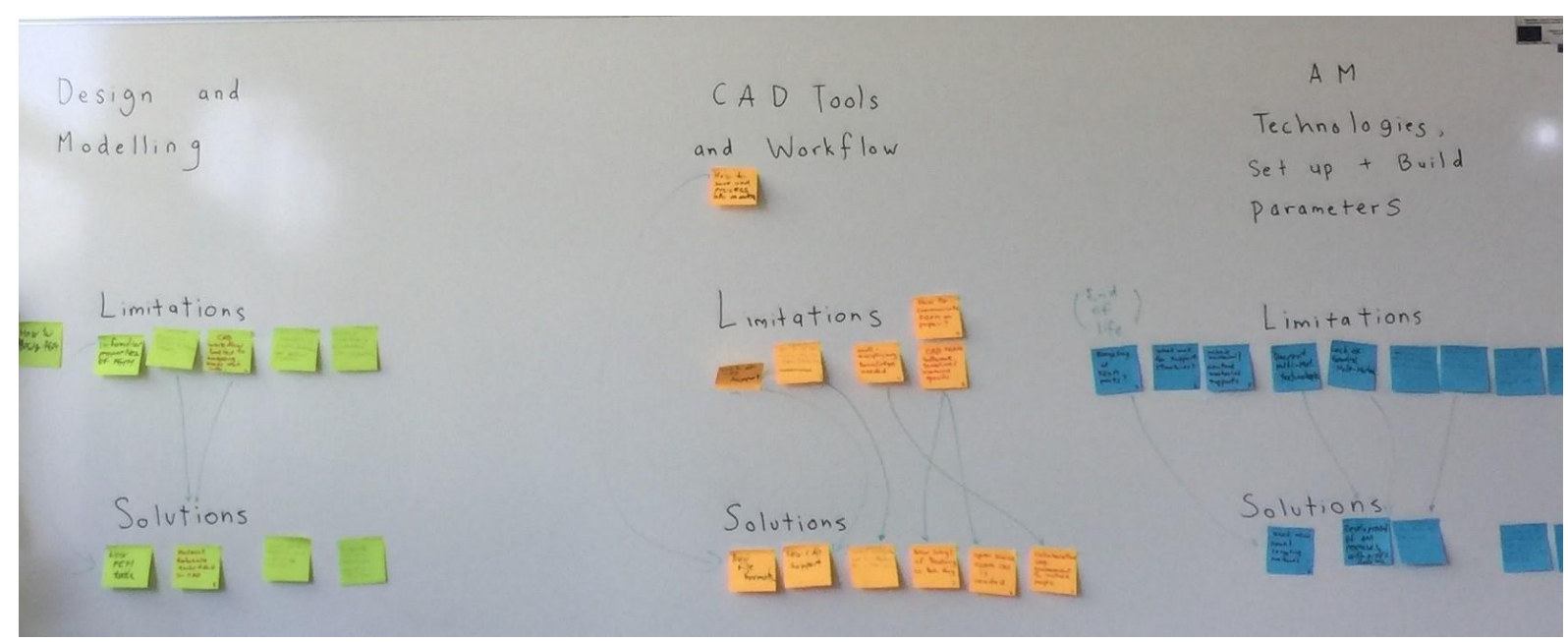

(c)

Figure 3. Participants put their opinion during a discussion activity (a) difference between conventional multi-material AM and FGAM, (b) advances of FGAM, and (c) panel discussion on limitations and recommendations for FGAM

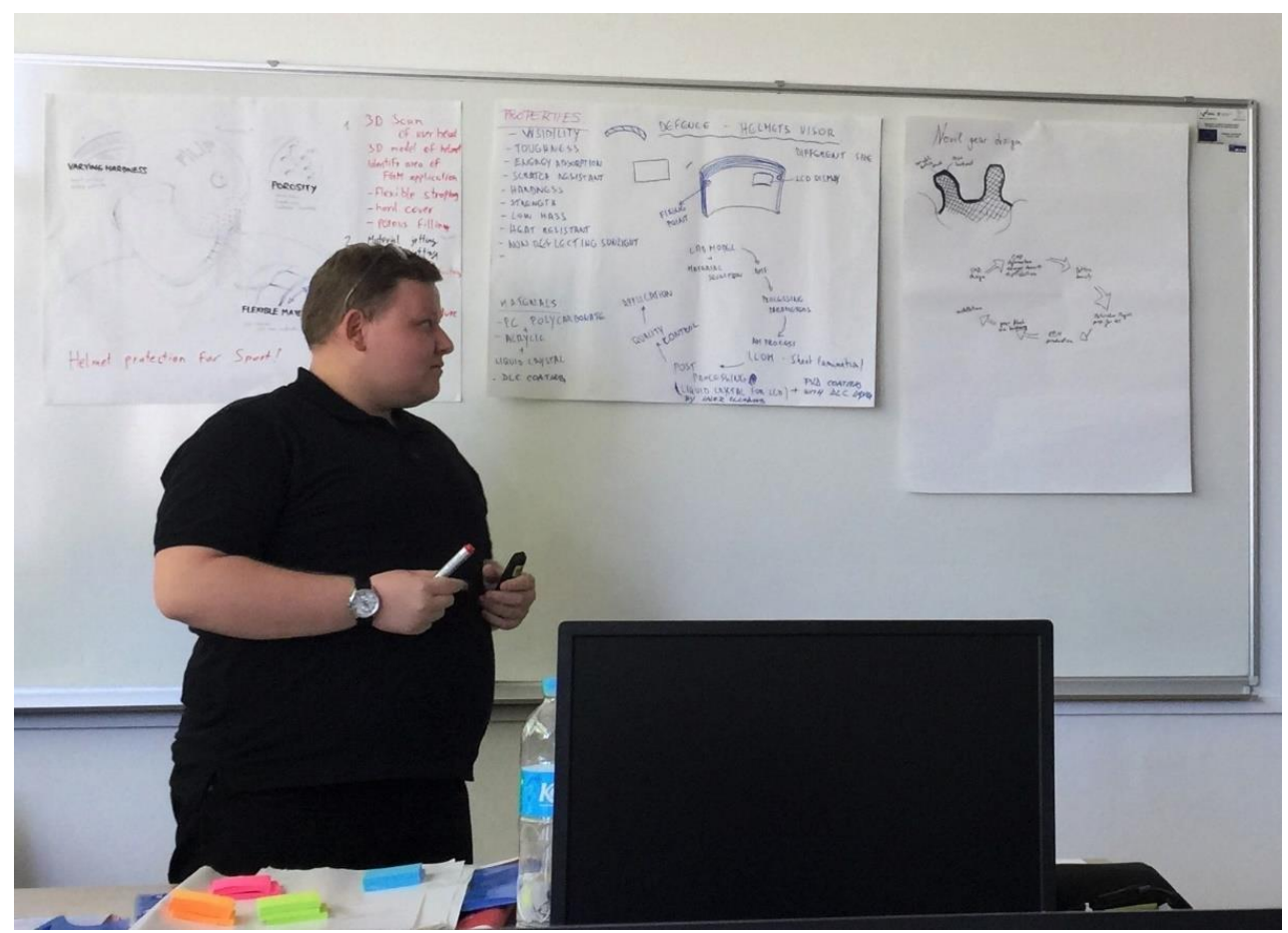

Figure 4. Participants were presenting their research findings on applications of FGAM and their design-manufacturing process chain 


\subsection{Online workshop survey: Validating the evaluation of LO}

An online survey was conducted to validate the evaluation of the fulfilment LO of the workshop. A well-known website, Survey Monkey was used to design and conduct the survey. Figure 5 presents a sample of the survey questionnaire. The list of questions was included in Appendix A. The survey links requesting their feedback were emailed to the attendees after the workshop. The attendance of the participants was recorded at the beginning of the workshop. This survey served as a triangulation method (Ghrayeb et al., 2011) to converge all assessment data from the discussions, activity and observations with a view to reinforcing the teaching curricula for FGAM through this case study.

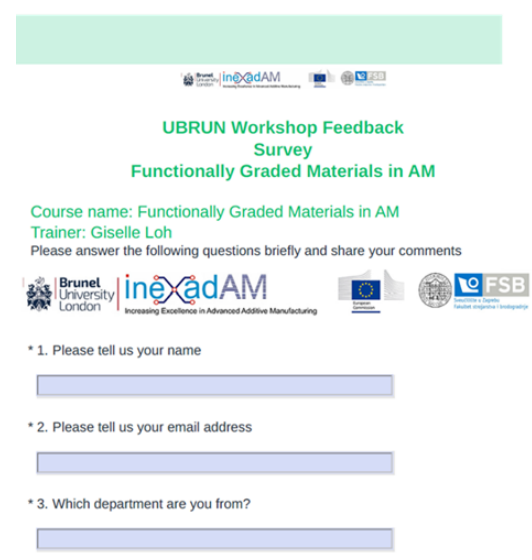

Figure 5. The evaluation survey question to test the participant's reflection on learning outcomes of the workshop

\subsubsection{Analysis and outcome of the online survey}

The workshop was attended by 7 academics and a $\mathrm{PhD}$ researcher. The background of the attendees was recorded from the survey and is presented in Figure 6. The answers from all attendees are downloaded from the survey website and analysed following the qualitative approach of data analysis called thematic analysis. The qualitative data analysis from an interview or workshop survey is commonly practised in nursing and other education science (Vaismoradi et al., 2016). In thematic analysis participants' perspectives to each question was converted to textual data and inferred into information by a systematic theme construction approach. The theme is the deduced information which forms the practical results of the study. The objective of this survey was to test the teaching approach evaluating fulfilment of the learning outcomes and reflection from the participants on their expectation in that subject area. In this survey, participants' answers to the questions from 6 to 10 are analysed in different steps: 1) coding 2) classifying and comparing, 3) labelling 4) defining and constructing theme and 5) connect the theme with the objective of survey. The data are analysed by hand using Microsoft word processor and highlighter. The themes were constructed and colour-coded based on the survey questions using top-down thematic analysis approach and open coding technique (Clarke and Braun, 2013).

The survey feedback said that learners found very useful all pieces of information on classification, manufacturing processes, and lattice structure design for FGAM. From the survey data, $57 \%$ of learners expressed interest to know more in the design process for FGAM, and 29\% in the material modelling, testing and qualifying FGAM parts. Among the participants, $43 \%$ emphasised learning more about the current practice of FGAM, in comparison to product quality produced in both conventional and AM routes. The attendees highlighted the need to find out about material compatibility for FGAM, methods of design functionality or composition gradation and qualifying AM technologies for FGAM. Some researchers were also interested in the voxel-based FGAM process. Thus, the survey data evidenced the fulfilment of LO and helped find need of further knowledge of FGAM to extend the learning curriculum, through participants' feedback. 

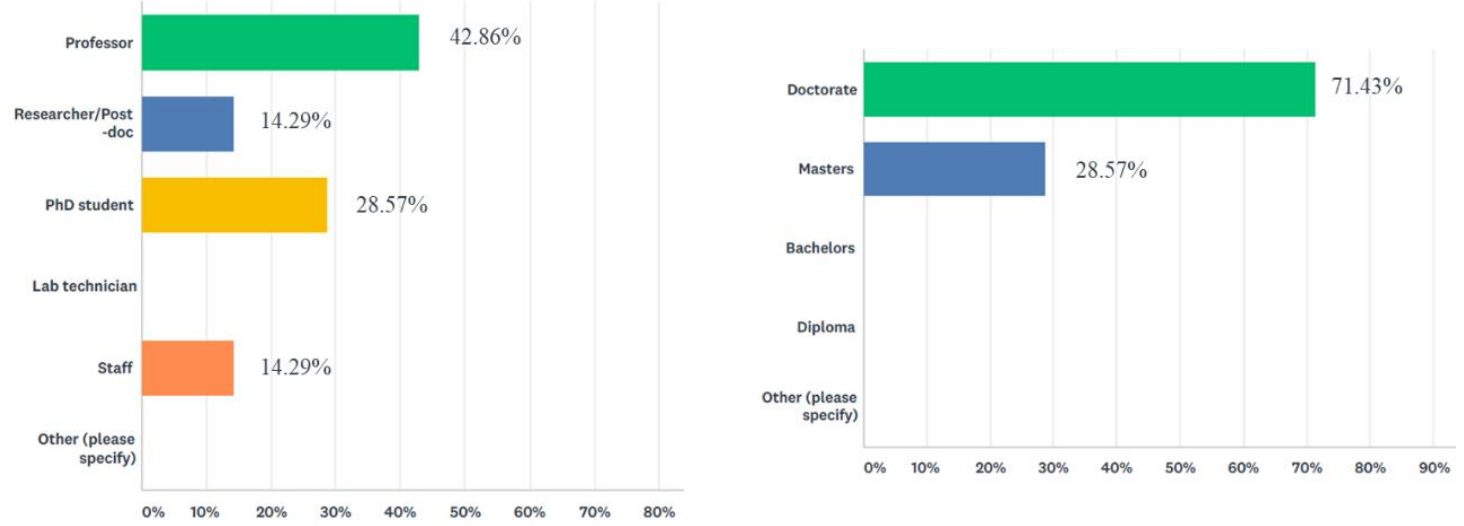

Figure 6. The profession and qualification of the attendees in the FGAM workshop

\section{Conclusion and findings}

A workshop-based teaching case study on FGAM was successfully conducted by UBRUN and UNIZAG on the INEX-ADAM platform. The workshop presented an overview of the FGAM process chain, including the design, manufacturing and applications to a small group of academics and researchers. The teaching model utilised mixed teaching and assessment methods including content focused lectures, interactive panel discussions and project-based activity. The workshop enabled the academic and researcher enhancing knowledge in FGAM and identified the need and gaps for research and education of FGAM in Croatian context. The online survey validated the level of fulfilment of learning objectives by analysing and statistically verifying learners' feedback on teaching contents and structure. The survey data will be helpful to reinforce and extend the workshop curriculum aiming to a wider dissemination model.

This workshop was limited to the classroom teaching providing only the theoretical overview of FGAM. In future, to increase participants from academia and industry, a demonstration on functionally graded scaffolds design and manufacturing process could be introduced. In addition, onsite training collaborating with industry or a laboratory session of applying additive technology to build a part could also be integrated into the revised curriculum. Material modelling and voxel-based design modelling could also be included in future. These initiatives will help enhance the research capabilities to mitigate the gaps and limitation on the potential applications of FGAM for the medical, automotive and tooling industries.

\section{Acknowledgement}

The work is supported by the Increasing Excellence on Advanced Additive Manufacturing (INEX-ADAM), an EU funded project (H2020-WIDESPREAD-05-2017-Twinning-810708). To know more about the project please visit the website, www.inex-adam.eu.

\section{References}

Brunel University London. (2020), Brunel on Design. [online] Available at: https://www.brunel.ac.uk/design/ brunel-on-design/brunel-on-design [Accessed 12 Feb. 2020].

Clarke, V. and Braun, V. (2013), "Teaching thematic analysis: Overcoming challenges and developing strategies for effective learning", Psychologist, Vol. 26 No. 2, pp. 120-123.

Culatta, R. (2020), Andragogy (Malcolm Knowles). [online] InstructionalDesign.org. Available at: https://www.instructionaldesign.org/theories/andragogy/ [Accessed 12 Feb. 2020].

Fry, H., Ketteridge, S. and Marshall, S. (2009), A Handbook for Teaching and Learning in Higher Education, 3rd ed., Taylor \& Francis, New York and London.

Ghrayeb, O., Damodaran, P. and Vohra, P. (2011), "Art of triangulation: an effective assessment validation strategy", Global Journal of Engineering Education, Vol. 13 No. 3.

Learning and Teaching Hub @Bath. (2020), Events and Workshops. [online] Available at: https://teachinghub .bath.ac.uk/events-and-workshops/ [Accessed 12 Feb. 2020]. 
Loh, G. et al. (2018), “An overview of functionally graded additive manufacturing”, Additive Manufacturing, Vol. 23, pp. 34-44.

NFER. (n.d.), An introduction to formative and summative assessment. [online] Available at: https://www.nfer. ac.uk/for-schools/free-resources-advice/assessment-hub/introduction-to-assessment/an-introduction-toformative-and-summative-assessment/ [Accessed 12 Feb. 2020].

Palis, A. and Quiros, P. (2014), “Adult learning principles and presentation pearls”, Middle East African Journal of Ophthalmology, Vol. 21 No. 2, p. 114.

Pei, E. and Kabir, I. (2019), Report on Curricula for Training and Knowledge Transfer.

Pei, E. and Kabir, I. (2019a), Master Report on Partners' Resources, Expertise and Projects.

Pei, E. and Loh, G. (2019), "Future Challenges in Functionally Graded Additive Manufacturing", In: Pei, E., Monzón, M. and Bernard, A. (Eds.), Additive Manufacturing-Developments in Training and Education, 1st ed. Springer International.

Simpson, T., Williams, C. and Hripko, M. (2017), "Preparing industry for additive manufacturing and its applications: Summary \& recommendations from a National Science Foundation workshop", Additive Manufacturing, Vol. 13, pp. 166-178.

Vaismoradi, M. et al. (2016), "Theme development in qualitative content analysis and thematic analysis", Journal of Nursing Education and Practice, Vol. 6 No. 5.

Voxcad Tutorial 1: Overview (29 Jan 2011) YouTube video, added by Jonathan Hiller [Online]. Available at: https://www.youtube.com/watch?v=utWE1j8s95U (accessed 22 November 2019). 


\section{Appendix A}

The workshop evaluation survey questions are devised in the following format.

Workshop Name

Date Instructor Name

\section{Section A-Participant's professional background}

1. Participant name

2. Participant email address

3. Please specify your profession in the University

4. Which department do you work?

5. What is the highest level of qualification do you have?

\section{Section B-Functionally Graded Materials in AM}

6. Which aspects of the Functionally Graded Materials (FGM) in Additive Manufacturing workshop do you find most useful to you?

7. Which subjects on Functionally Graded Materials (FGM) in Additive Manufacturing would you like to know more?

8. Are there any areas of Functionally Graded Additive Manufacturing (FGAM) that you wish to be covered in this workshop?

9. Based on the FGAM process chain as discussed during the workshop, please state the greatest limitation(s) or concern(s) that should be prioritised to be addressed, in terms of Material, Additive Manufacturing Technology and CAD tools.

10. Does any of the discussed topics in the Functionally Graded Materials (FGM) have a connection with your research or study? If yes, could you please identify the subject area? 